BANCA D'ITALIA

E U R O S I S T E M A

Questioni di Economia e Finanza

(Occasional Papers)

Has the wage Phillips curve changed in the euro area?

by Guido Bulligan and Eliana Viviano 



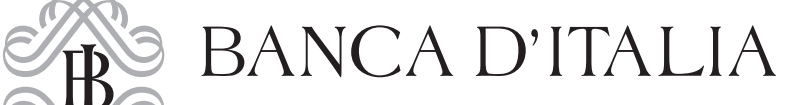

E U ROS I S T E MA

\section{Questioni di Economia e Finanza}

(Occasional papers)

Has the wage Phillips curve changed in the euro area?

by Guido Bulligan and Eliana Viviano

Number 355 - September 2016 
The series Occasional Papers presents studies and documents on issues pertaining to the institutional tasks of the Bank of Italy and the Eurosystem. The Occasional Papers appear alongside the Working Papers series which are specifically aimed at providing original contributions to economic research.

The Occasional Papers include studies conducted within the Bank of Italy, sometimes in cooperation with the Eurosystem or other institutions. The views expressed in the studies are those of the authors and do not involve the responsibility of the institutions to which they belong.

The series is available online at www.bancaditalia.it.

ISSN $1972-6627$ (print)

ISSN 1972-6643 (online)

Printed by the Printing and Publishing Division of the Bank of Italy 


\title{
HAS THE WAGE PHILLIPS CURVE CHANGED IN THE EURO AREA?
}

\author{
by Guido Bulligan* and Eliana Viviano*
}

\begin{abstract}
Increasing evidence shows that after a flattening occurred in the immediate aftermath of the global financial crisis, the relationship between price inflation and economic slack became stronger in the euro area. By contrast, there is no clear evidence of a strong(er) relationship between wage inflation and unemployment. In this paper we estimate a standard Phillips curve with time-varying coefficients separately for Italy, Spain, Germany and France. We find that, with the exception of Germany, after the global financial crisis the sensitivity of hourly wage changes to labour market slack increased. Second, using administrative microdata available only for Italy, we relate daily wage changes to the local unemployment rate. The results confirm the steepening of the Phillips curve after 2008, also when controlling for composition effects.
\end{abstract}

JEL Classification: E24, E31, E58.

Keywords: wage growth, Phillips curve, parameter instability.

\section{Contents}

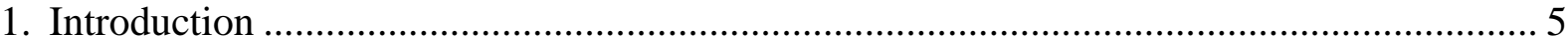

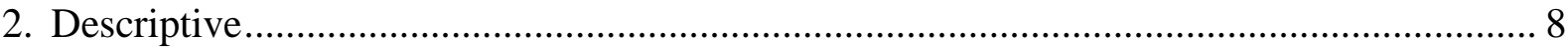

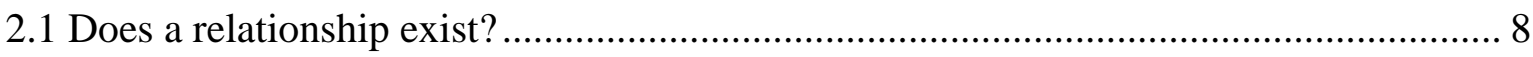

2.2 Has the relationship changed? Preliminary evidence.................................................. 9

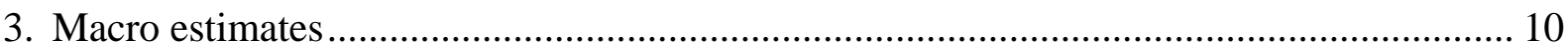

3.1.Testing for the instability of the Phillips curve ............................................................. 10

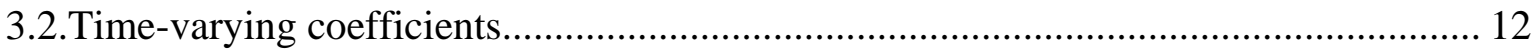

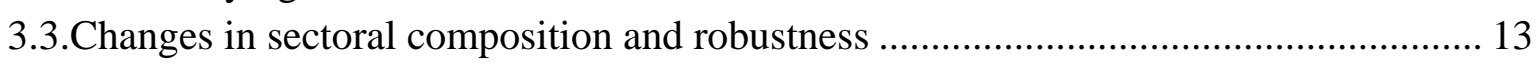

4. What is (not) behind the steepening? Evidence from Italy ............................................. 14

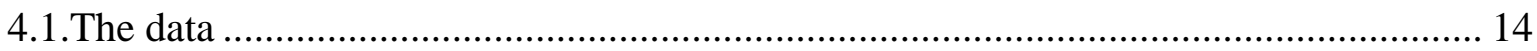

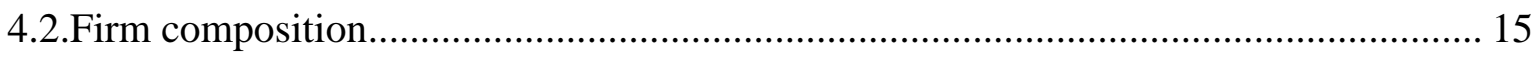

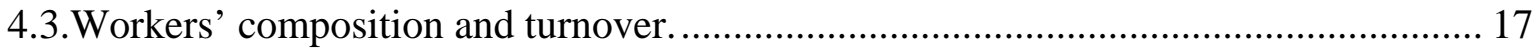

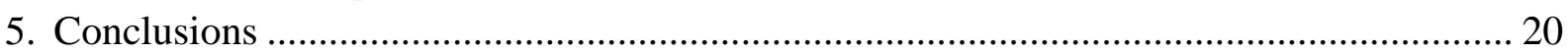

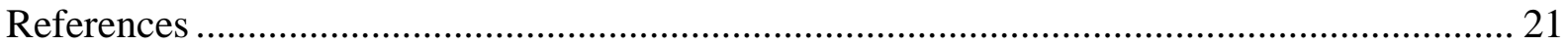

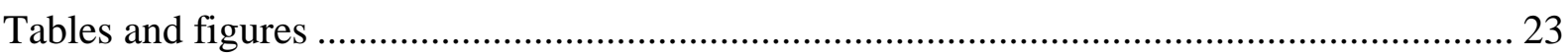

\footnotetext{
* Bank of Italy, Directorate General for Economics, Statistics and Research. We thank Stefano Marucci for valuable research assistance, Effrosyni Adamopoulou, Emmanuele Bobbio, Marta De Philippis and Federico Giorgi for helpful discussions, and Matteo Bugamelli, Fabio Busetti, and Paolo Sestito for comments. The views expressed here are solely ours; in particular, they do not necessarily reflect those of the Bank of Italy.
} 



\section{Introduction}

After the global financial crisis the debate about the short-run determinants of inflation has gained momentum. In the US, where empirical evidence supports (if any) the hypothesis of a flattening of the Phillips curve (PC; see Blanchard 2016 for a critique $^{1}$ ), the debate started immediately after the Global financial crisis, with the socalled "missing disinflation puzzle" (see , e.g. IMF, 2013) and continued after the subsequent recovery (the "missing inflation puzzle"). Various explanations have been proposed. According to some studies the flattening of the PC is caused by firms' and household expectations (e.g. Coibion and Gorodnichenko, 2015; Davig, 2016, propose a model which explains PC parameter instability). For others it depends on downward nominal wage rigidities (e.g. Daly and Hobijn, 2014).

In the euro area the empirical evidence is rather mixed. From the one hand there are increasing signs that in recent years the negative relationship between inflation and economic slack has become stronger (see e.g. Riggi and Venditti, 2015). From the other, it is not clear whether also the correlation between nominal wage growth and unemployment, indeed quite weak, has changed too.

The euro area labour market is undoubtedly heavily regulated by several institutions affecting, directly or indirectly, wage determination and the possibility to adjust nominal wages in case of a shock (minimum wages, high unionization, automatic extension procedures, limited opting-out). ${ }^{2}$ In spite of high rigidities, however, there is also evidence that wages respond to cyclical conditions. For instance, Rosolia (2015), finds that in Italy negotiated wage growth is negatively affected by labour market slack. The correlation of aggregate actual wages and unemployment is however quite weak because of the long duration of centrally-bargained job contracts (3 years in Italy). Jimeno et al. (2016), using the data of a survey conducted by the European central banks within the "Wage Dynamics Network" project (WDN), show that, in spite of the

\footnotetext{
${ }^{1}$ Indeed, the debate about a flattening of the PC in advanced economies started before the Global financial crisis. Borio and Filardo (2007) relate it to a structural change due to globalization and the stringer competitive pressure of Asian economies. Gaiotti (2010), using firm-level data confirms the existence of a flattening, but finds that it is not related to globalization but is probably related to the moderate dynamics of inflation expectations.

${ }^{2}$ Nominal base wage rigidities, however, are due not only to institutions, but can arise because of firms' and workers' behaviour. If wages determine workers' effort, a nominal wage cut could reduce effort and productivity, discouraging firms to adopt such a strategy (e.g. Daly and Hobijn, 2014). Whatever the reason behind them, downward nominal wage rigidities typically flatten the Phillips curve.
} 
presence of institutional rigidities preventing nominal and real wage cuts, during the period 2010-13 more than 20 per cent of French and Spanish firms hit by a shock could freeze or cut wages. This share was equal to 17 per cent in Italy and 11 per cent in Germany. Using the same micro data, in Section 2 we show that in the euro area both the probabilities to adjust base wages and the variable component of wages correlate with the unemployment rate. The focus of this paper, however, is not wage flexibility per se. Instead, we look at changes in the aggregate relationship between wage growth and unemployment after 2008.

In the literature there is no consensus on the possible causes of non-linearities, so that it is not clear whether the Phillips curve is steeper in a boom or in a recession. ${ }^{3}$

First, it is possible that in deep and prolonged recessions, as the one started in 2008, wages are more reactive to slack, as workers and unions are more willing to accept a wage cut in order to preserve employment (see, for instance, Giannone et al., 2014, for empirical evidence of non-linearities at extreme values of unemployment).

Non-linearities can also be due to wage setting reforms. This explanation, however, cannot be generalized to the euro zone, but it is probably valid only for those few countries, like Spain and Greece, undertaking substantial reforms in this area.

The steepening/flattening of the PC can also be caused by changes in the composition of workers, due to hiring and firing decisions of firms. A steepening of the PC may occur if workers with more flexible wages are more likely to remain employed in recessions. On the opposite side a flattening occurs if during a recession firms prefer to hoard more productive (and highly paid) labour.

Last, also firms' entry and exit can affect aggregate wage dynamics. This may happen for instance if more productive firms are also more likely to remain in the market during downturns. Conversely, it could also happen that market forces tend to select firms with a more flexible wage structure.

Also existing empirical evidence on the mechanisms behind wage adjustments is rather mixed. Adamopoulou et al. (2016a), using microdata for Italy, find that after 2008 Italian firms used fixed-term workers to slow down the dynamics of wages. Anderton and Bonthius (2015) find evidence of a flattening of the PC in the euro area,

\footnotetext{
${ }^{3}$ Different explanations based on the relationship between firms' pricing decisions and capacity utilization, support the hypothesis of (short-rum) non-linearities when market slack is very low (e.g. Clark, Laxton and Rose, 1996, for the US case).
} 
but they also find that the slope of the PC increases the higher is the use of temporary workers. Adamopoulou et al. (2016b) show that in Italy a non-negligible share of the evolution of wages can be attributed to changes in the composition of firms.

In this paper we present both macro and micro evidence supporting the hypothesis of a steepening of the wage Phillips curve in the largest euro area countries after 2008. First, we focus on Germany, France, Italy and Spain, and by estimating country-specific Phillips curves, we carry out a set of tests for parameter instability. Overall, the tests support the hypothesis that the slope of the PC changed after 2008. Second, we carry out time-varying regressions for the same set of countries and two PC alternative specifications. We find evidence of a steepening of the PC with respect to unemployment after 2008 in France, Italy and Spain, but not in Germany, where it is still steeper than in the other euro area countries but became flatter than in the past after the Global financial crisis. We then focus on Italian microdata. First, we investigate firm composition effects. In a setting which controls for firms' entry and exit, as well as firm unobservable characteristics, we estimate how average wage changes react to the local unemployment rate. We find evidence of an increase in wage flexibility at the firm level after 2008 and no evidence that changes in the composition of firms explain the steepening of the PC.

Last, we focus on workers. Our data do not allow us to separately analyse the dynamics of base and variable wage components. So we focus on workers' composition effects. We estimate the correlation between individual wage changes and the local unemployment rate in different samples of incumbent workers and fixed-term workers. In all specifications we find a steepening of the PC. We then conclude that the higher elasticity of wages to labour market slack found in aggregate data after 2008 is not (only) driven by composition effects.

This paper is organized as follows. In section 2 we present evidence, based on aggregate and firm-level data, confirming that in the euro area, in spite of existing institutional rigidities, wage growth negatively correlates with labour market slack. This is a preliminary step for formally testing the hypothesis of changes in the slope of the PC. The results of the tests are presented in Section 3. In section 4 we present micro estimates for Italy, which allow us to control for a very wide sources of composition effects. Section 5 briefly concludes. 


\section{Descriptive}

\subsection{Does a relationship exist?}

We first check for the existence of a negative correlation between wage growth and unemployment. We start the analysis by estimating a reduced form statistical relationship between the unemployment rate and wage inflation. Figure 1 shows the scatterplots of the unemployment rate in the Euro area and annual nominal wage growth between 1999Q1 and 2015Q4. The corresponding OLS estimates confirm that the coefficient on the unemployment rate is equal to -0.25 and statistically significant.

Additional evidence can be derived from the third wave of the WDN survey including the four years from 2010 to 2013 (see Jimeno et al. 2016 for further details on the survey and a description of the main results). The sample is composed of over 17,000 firms in the euro area private sector. Among other things the survey collects data on whether the firm froze or cut base wages and whether the firm reduced variable components like bonuses. Since the data cover only this limited time span, we cannot check whether the slope of the wage PC increased with respect to the period preceding the Great Recession of 2008. Nevertheless we can at least check whether there is some correlation between the probability to adjust base and variable wages and the unemployment rate in country $c$ at time $t$ (with $t$ comprised between 2010 and 2013).

The results, for different outcomes are reported in Table 1. Column 1 refers to the probability to freeze wages in a given year; column 2 to the probability to cut wages; column 3 to the probability to reduce variable wages. Each regression includes firm fixed effects (which capture also country dummies), the unemployment rate and year dummies to capture euro area common trends. The correlation is then identified by country-specific changes in the country-level unemployment rate during the four years from 2010 to 2013. Data are weighted with employment weight to account for the different size of samples in each country. Standard errors are robust. ${ }^{4}$ All the estimates confirm the existence of a positive relationship between downward wage adjustments and labour market slack during the period considered.

\footnotetext{
${ }^{4}$ For Italy we have regressed the probability to adjust wages on the province-level unemployment rate, finding, for all the variables, similar results.
} 


\subsection{Has the relationship changed? Preliminary evidence.}

We then come back to aggregate macro variables and focus on the following basic model:

$$
\Delta^{4} \mathrm{w}_{\mathrm{t}}=\mathrm{c}+\beta \Delta^{4} \mathrm{w}_{\mathrm{t}-1}+\gamma \mathrm{U}_{\mathrm{t}}+\varepsilon_{\mathrm{t}}
$$

where $\Delta^{4} \mathrm{~W}_{\mathrm{t}}$ is the $\mathrm{y}$-o-y nominal hourly wage growth in the private sector and $\mathrm{U}_{\mathrm{t}}$, as in Figure 1, is the economy-wide unemployment rate. The lagged dependent variable $\Delta^{4} \mathrm{~W}_{\mathrm{t}-1}$ is aimed at capturing persistence in wage dynamics, while the unemployment rate proxies for labour market slack.

We estimate equation 1 recursively on an expanding window where the first sample is 1999Q1-2007Q4 which goes from the start of stage three of European monetary union to the Global financial crisis. Then we re-estimate the same equation adding one observation at a time. The last sample covers the period 1999Q1-2015Q4. This sub-period allows us to further neutralize possible remaining differences due to monetary policy before 1999. Figure 2 and Figure 3 report the estimated coefficient on the unemployment rate for the euro area and for its four biggest economies. The figures suggests that: i) the correlation between unemployment and wage inflation in the euro area is rather unstable over time. While remaining negative, its absolute value has decreased monotonically from the beginning of 2008 to 2012 but it has increased again - albeit marginally - after 2012 ii) its pattern over time reflects closely the pattern observed in Germany until 2012; iii) the euro area aggregates mask heterogeneous results across its four biggest economies. The relationship between wages and labour market slack seems to have become more negative in Italy and less negative in Germany (but still higher than in the other countries). In Spain, after a maximum around 2010 it has become more negative again, while in France has moved from being positively signed to being negligible. While equation 1 represents a very naïve descriptive model, it provides prima facie evidence in favour of parameter instabilities in the four major euro area countries. 


\section{Macro estimates}

In this section we adopt a time series approach to evaluate the case of timevarying sensitivity of wages to labour market conditions. We use country-by-country time series and we check whether there is evidence supporting the case for parameter instability after controlling for other determinants of wage inflation like past and expected inflation (e.g. Gali', 2009).

\subsection{Testing for the instability of the Phillips curve}

First we estimate a specification where wage inflation at time $t$ is a function of its own lags, the current or past unemployment rate and expected inflation, measured by the average inflation rate expected 6-quarter ahead by a sample of financial analysts surveyed by Consensus Economics.

$$
\Delta^{4} w_{t}=c+\sum_{i=1}^{k} \beta_{i} \Delta^{4} w_{t-i}+\delta E_{t} \Delta p_{t+1}+\gamma U_{t-h}+\varepsilon_{t}
$$

where lags between 0 and 4 are considered for the unemployment rate. As equation (1), equation 2 is consistent with theoretical models where wage inflation has some degree of persistence (staggered-contract models). However it also allows for wage inflation to respond to current and expected business cycle conditions (see Friedman 1968).

The first type of evidence is based on tests of parameter instability over the period 1999Q1-2015Q4. Under the null hypothesis, the parameters of the PC are stable, while under the alternative hypothesis they evolve as driftless random walks. As conventional break-point tests show low power when the break occurs towards the end of the sample, we resort to the tests suggested by Busetti (2012). According to the author the Locally Most Powerful test can be modified so as to achieve higher power.

The LMP test has the following form:

$L=\hat{\sigma}^{-2} T^{-2} \sum_{t=1}^{T} S_{t}^{\prime} V^{-1} S_{t}$

where $\hat{\sigma}^{2}=(T-K)^{-1} \sum_{t=1}^{T} \widehat{u_{t}^{2}}, S_{t}=\sum_{j=t}^{T} \widehat{u_{\jmath}} \widehat{x_{1 \jmath}}, V=T^{-1} \sum_{t=1}^{T} x_{1 t} x_{1 t}^{\prime}$ and $\hat{u}_{t}=y_{t}-$ $x_{t}^{\prime} \hat{\beta}$ are the OLS residuals from regressing $y_{t}$ on a set of $x_{t}$ variables for a subset of which we are interested in testing parameter instability $\left(\mathrm{x}_{1 \mathrm{t}}\right.$ which might include all $\mathrm{x}_{\mathrm{t}}$ variables). Busetti (2012) suggests to use the following variations to focus on breaks 
that occur only in the last fraction $\pi$ of the sample: $L(\pi)=\hat{\sigma}^{-2}(T-\pi T)^{-2} \sum_{t=\pi T+1}^{T} S_{t}^{\prime} V^{-1} S_{t}$ and to test parameter instability with:

$\operatorname{Sup}-L=\operatorname{Sup}_{\pi \in \Pi} L(\pi)$

$\operatorname{Exp}-L=\log \int_{\pi \in \Pi} \exp (L(\pi)) \pi d(\pi)$

The main idea behind these tests is to increase the power of original LMP tests by focusing on the latest part of the sample and additionally by giving increasing weight to observations close to the end of the sample (Exp-L). We test for a break in the last 25 per cent, the last 10 per cent of the sample and the interval covering 98 per cent of the sample.

The tests are run for 5 specifications of equation 1 where we let the parameter h, which controls the lag relationship between wage dynamics and the unemployment rate, range from 0 to 4 (for robustness) and keep $\mathrm{k}$, the parameter controlling the number of lags of wage growth, fixed to 1 . Table 2 collects the average (across values of h) results for tests conducted on all coefficients (Panel a) and on the coefficient on the unemployment rate alone (panel b). Since values close to 1 are supportive of parameter instability (see note to the table), we find clear evidence of parameter instability for Italy and Germany, mixed evidence for Spain (which is the results of stronger evidence when lags of the unemployment rate are used) and no evidence for France.

We run the same tests also on a slightly different specification of the PC where we substitute past wage dynamics for past inflation dynamics.

$$
\Delta^{4} w_{t}=c+\sum_{i=1}^{k} \beta_{i} \Delta^{4} p_{t-i}+\delta E_{t} \Delta p_{t+1}+\gamma U_{t-h}+\varepsilon_{t}
$$

This alternative specification relates more closely to the PC derived in new Keynesian models (see for instance Galí, 2009) as it states that only a fraction of workers face a wage adjustment in any period and that workers, who do not re-set their wages at time $t$, will see their wages grow in line with past realized inflation. Also under this specification there is clear evidence in favor of parameter instability for Italy and 
Germany and mixed evidence for Spain. However there is also evidence in favor of instability for France (see Table 3).

\subsection{Time-varying coefficients}

The second type of evidence is based on time varying parameter regressions. More specifically we explicitly allow the parameters in equations 2 and 6 to vary over time (before doing that we set $\mathrm{h}=0$ and $\mathrm{k}=1$ ):

$\Delta^{4} w_{t}=c_{t}+\beta_{t} \Delta^{4} w_{t-1}+\delta_{t} E_{t} \Delta p_{t+1}+\gamma_{t} U_{t}+\varepsilon_{t}$

or alternatively,

$\Delta^{4} w_{t}=c_{t}+\beta_{t} \Delta^{4} p_{t-1}+\delta_{t} E_{t} \Delta p_{t+1}+\gamma_{t} U_{t}+\varepsilon_{t}$

Following Riggi and Venditti (2015) we resort to the kernel-based nonparametric estimators proposed by Giraitis et al. (2013). This type of estimators is based on the idea that in the presence of structural breaks, older observations should be discounted more than more recent ones. Giraitis et al. (2013) find that such methods performs well in forecasting several US macroeconomic series. In a subsequent paper Giraitis et al. (2014) show that they also are consistent and asymptotically normally distributed and, most important for our purposes, have very good small sample properties. As suggested by the authors we choose a Gaussian kernel and set the discounting parameter to $H=T^{r}$ where $r=0.5$. However unlike the authors, we use a one sided kernel which at each time $t$ only considers current and past observations. It follows that the estimated parameter instability between consecutive periods $t$ and $t+1$ is due both to a new data point entering the estimation sample as well as changes in the weighting structure. Figures 4 (a) and (b) show the time varying $50^{\text {th }}, 16^{\text {th }}$ and $84^{\text {th }}$ percentiles of the distribution for the parameter of the unemployment rate, the so-called "steepness" of the PC for the two specifications tested.

Both figures confirm that the responsiveness of wage dynamics to the unemployment rate has changed since the pre-crisis period. In particular for Germany, the data support the existence of a Phillips curve and suggest a flattening of the slope. On the contrary for Spain and Italy, while before the crisis the Phillips curve is not supported by the data (the coefficient on the unemployment rate is either zero or 
positive $^{5}$ ), after the crisis we find a negative relationship. Finally for France, we find mixed results, while the data are not consistent with the implication of the Phillips curve if specified as in eq.1 (the coefficient on the unemployment rate is positive throughout the whole sample), they are more in line with a Phillips curve after 2011 according to the alternative specification.

According to the (median) results for the first specification (eq. 2bis), at the end of 2015 an increase by 1 percentage point (pp) in the Italian unemployment rate is associated with a decrease by $0.15 \mathrm{pp}$ in annual wage inflation on impact and with a decline by $0.3 \mathrm{pp}$, after accounting for the lag structure. Very similar results are found for Spain. In Germany, despite the recent flattening, wage inflation changes are slightly stronger ( $0.4 \mathrm{pp}$ and $0.6 \mathrm{pp}$ respectively), while in France the short-run change of wage inflation is modest (0.02 pp) and not significant (it is close to $-0.5 \mathrm{pp}$ accounting for lags, although not significant). The alternative specification (eq. 6bis) does not distinguish between short-run and long-run correlation and as far as the latter are concerned these are in line with the estimates obtained from the first specification.

\subsection{Changes in sectoral composition and robustness}

So far, the results refer to the whole private sector. However, it is interesting to look at sector specific wage changes as results could differ substantially between labor vs capital intensive sectors or depend on the type of worker and contract prevailing in specific sectors. Moreover results for the whole private sector could be driven by changes in the relative weight of the manufacturing sector, typically considered as more rigid and more unionized, and the service sector. So, carrying out different estimates for each sector allows us to control for changes in the simplest source of composition effects, i.e. sectoral composition occurring after 2008. We re-run the analysis looking at hourly wages for industry and services separately (according to the NACE classification), while, absent sector specific measures of labor market slack, we keep using the total economy unemployment rate. Again results are shown for both specifications and reported in Figure 5 (a) and (b).

\footnotetext{
${ }^{5}$ In Italy, with the exception of the years following 2008, robust evidence of a PC can be found only for the Seventies (see Visco, 1984).
} 
For Italy there is evidence of increased responsiveness of wage growth to the unemployment rate in both industry and services. For Spain the increased steepness seems to reflect changes in the service sector while in the industrial sector since the crisis the responsiveness of wages has stopped declining. For Germany the decline in responsiveness reflects both industry and service developments, while in France a nonsignificant relationship between wage growth and the unemployment rate is confirmed by sector specific results.

If we look at the second specification, the results are broadly similar to those obtained under the first specification with the exception of France where the evidence of increased responsiveness found for the whole private sector reflects developments in both industry and services.

So far we have performed the analysis for given parameters regarding the amount of discounting of past data and the lag relationship between wage growth and the unemployment rate. In order to shed light on the role of the discounting factor in shaping results Figure 6 shows how the latter changes for different values of the parameter $\mathrm{H}$ (which in our setting controls the amount of discounting), while in Figure 7 we show the results obtained under different lag structures. Regarding the discount factor, starting from the benchmark case $\left(r=0.5\right.$ and therefore $\left.\mathrm{H}=\mathrm{T}^{0.5}\right)$ as we reduce the amount of discounting applied to past data ( $\mathrm{r}$ increases), the degree of parameter instability declines but does not vanish. Figure 7 shows instead the effect of changing the lag-relationship between unemployment and wage dynamics. For Italy, France and Germany the results do not seem to depend from the choice of this parameter, while for Spain results are more sensitive to it.

\section{What is (not) behind the steepening? Evidence from Italy}

\subsection{The data}

To check for the robustness of our results we rely on a single country, Italy, and on microdata on firms and workers. In particular we focus on how wage growth responds to the local province-level unemployment rate. ${ }^{6}$ Data on wages consist of

\footnotetext{
${ }^{6}$ While there is a huge literature on the responsiveness of the PC at the local unemployment rate (see e.g. Bodo and Sestito, 1994, for Italy, more recently Gregg et al., 2014, for UK), empirical studies on the wage PC at the local level are rather scant.
} 
social security payments made by all private-sector firms with at least one employee to the Italian National Social Security Institute (INPS). From this master data, INPS extracts two datasets. The first consists of the universe of firms and, for each firm, it includes the average number of employees and firms' wage bill, together with a firm unique identifier and the province where the firm is located. It is then possible to calculate average wages. The last available data refer to year 2013. The second consists of the employment histories of all workers born on the 1st or the 9th day of each month (6.5 per cent of total workforce in the Italian private sector). The worker extraction, updated to 2014, provides information on demographics, the annual gross wage, the number of days worked, the main characteristics of the contract, maternity and sick leave, as well as whether the worker benefits from the Italian wage supplementation scheme, Cassa integrazione guadagni (CIG). The province-level unemployment rate is released by the Italian National Statistical Institute (Istat) since 2004.

\subsection{Firm composition}

We first look at firms' adjustments and we estimate the following equation using data from 2004 to 2013:

$$
\Delta w_{t f p}=\delta_{t}+\delta_{f}+\beta \Delta w_{t-1, p f}+\delta_{1} U_{t, p}+\delta_{2} U_{t, p} * D_{p o s t 2008}+\epsilon_{t f p}
$$

where all data have an annual frequency, $\Delta w_{t f p}$ is the y-o-y change in the average gross salary paid to employees by firm $f$-th, located in province $p$; $\delta_{t}$ and $\delta_{f}$ are time and firm fixed effects and $U_{t, p}$ is the unemployment rate in province $p$ at time $t$. Since the number of firms which change province each year is negligible, the term $\delta_{f}$ captures also province-level characteristics. The dummy $D_{\text {post2008 }}$ is equal to 1 if the observation refers to a year between 2008 to 2013 (0 otherwise), and $\delta_{2}$ captures changes in the elasticity of the PC after 2008. Equation [7] allows us to strictly control for confounding factors affecting firms' labour cost evolution. The identification of the slope of the PC and its steepening is then based on the variability of the unemployment rate across provinces, whereas the impact of inflation expectations, which (reasonably) do not vary at the local level, is captured by time fixed effects. 
The coefficients $\delta_{1}$ and $\delta_{2}$ should however partly capture also the reaction of wages to the aggregate unemployment rate. We then estimate the following equation:

$$
\Delta w_{t f p}=\delta_{f}+\beta \Delta w_{t-1, p f}+\delta_{1} U_{t, p}+\delta_{2} U_{t, p} * D_{p o s t 2008}+\delta_{3} E_{t} \Delta p_{t+1}+\epsilon_{t f p}
$$

where time dummies are skipped and aggregate shocks, which include also wage increases set by nation-wide collective agreements, are captured by inflation expectations $E_{t} \Delta p_{t+1}$. The coefficients $\delta_{1}$ and $\delta_{2}$ represent then the correlation between the unemployment rate and wage growth not captured by the correlation between wage growth and inflation expectations. Since both equations 7 and 8 include the lagged value of the dependent variables, estimates can be biased (and since we are using panel data this bias does not vanish as the time dimension of our dataset increases). Thus, we estimate equation 8 also by the use of a GMM estimator. An additional advantage of equation 8 is that it allows for GMM estimates based on first differences.

Preliminarily, consider Figure 8, which reports the y-0-y elasticity of wage growth to the unemployment rate, obtained by estimating equation [7] on the interactions among $U_{t, p}$ and time fixed effects. ${ }^{7}$ Overall, we find a negative relationship between wage changes and unemployment, entirely determined by the increase of elasticity from 2009 onwards. (The positive spike in year 2008 has been probably due by the growth of the base wage component determined by collective pay agreements, mostly renewed in 2008, i.e. before the reform of collective bargaining undertaken by social partners in 2009).

In Table 4 instead we report the results obtained by estimating equation 7 (column 1) and equation 8 (columns 2 and 3, OLS and GMM estimators respectively).

Table 4 is also split into 3 parts. The upper one refers to the whole population of firms. In column 1, which is based on Equation 7, the effect of province level differences in the unemployment rate on wage growth is rather small and significant only after 2008. In the second column, referring to equation 8 (OLS estimator), the correlation between the unemployment rate and wage growth is larger, being $\delta_{1}$ equal to -.225 and highly significant. Interestingly after 2008 the correlation increases and the new slope of the PC is -.291 (-.225 plus -.066), a value not so far from to the one

\footnotetext{
${ }^{7}$ Of course, also the term $\delta_{2} U_{t, p} * D_{\text {post2008 }}$ is excluded.
} 
obtained by macro estimates. The last column reports the GMM estimates which confirm the main findings. In columns 2 and 3, interestingly, the coefficient on inflation expectation is positive, even if rather small.

We then control for possible selection bias induced by firm entry and exit. For instance, if during the Global financial crisis firms with higher wage growth are more likely to exit the market, then our estimates are biased upward. The same happens if after 2008 only firms with lower wage growth enter the market.

To address this potential source of bias, in the central part of the Table we select all firms which were already operating before 2007, i.e. before the Crisis, and we reestimate equations [7] and [8] on this subsample. Again we find an increase in the elasticity of average wage growth to local unemployment (column 1) which rises further when we estimate equation 8. Also when we consider a sample composed only of firms which did not exit the market during the period 2008-13 (bottom part of Table 4) the results confirm a significant steepening of the PC after 2008. We then conclude that the steepening of the PC does not depend on changes in the composition of firms.

\subsection{Workers' composition and turnover.}

By using the random sample of employees described in Section 4.1, we now focus on workers, by replicating what already done for firms. Preliminarily, since compensation through CIG is only partial and workers in CIG face a decrease in nominal wages, we skip them from the analysis.

We estimate the same model as in [7], which is now equal to:

$$
\Delta w_{i p t}=\delta_{t}+\delta_{i}+\beta \Delta w_{t-1, p, i,}+\delta_{1} U_{t, p}+\delta_{2} U_{t, p} * D_{\text {post } 2008}+\epsilon_{i p t}
$$

where $i$ denotes the $i$-th individual, $p$ the province where the $\mathrm{i}$-th individual works, $t$ is time and $\delta_{i}, \delta_{t}$ are the corresponding fixed-effects. As before, the parameter $\delta_{1}$ captures the correlation between the local unemployment rate and wage growth net of aggregate time trends, while $\delta_{2}$ captures changes in the elasticity after 2008. As before, we do not need to include province fixed effects as they are taken into account by individual fixed effects. As in section 4.2 we also estimate:

$$
\Delta w_{i p t}=\delta_{i}+\beta \Delta w_{t-1, p i}+\delta_{1} U_{t, p}+\delta_{2} U_{t, p} * D_{\text {post } 2008}+\delta_{3} E_{t} \Delta p_{t+1}+\epsilon_{i p t}
$$


where we refer to individual $i$ instead of $\operatorname{firm} f$.

The bottom part of Figure 8 refers to equation [7bis] and reports the estimated elasticities of $\delta_{1}$ interacted with time dummies (and estimated by excluding $\delta_{t}$ and $\delta_{2} U_{t, p} * D_{\text {post } 2008}$, as for firms). Once again, we find a negative relationship between wage changes and unemployment, entirely determined by the increase in the elasticity from 2009 onwards.

Table 5 is divided into 3 parts, corresponding to different samples and 3 columns. In the upper part of the Table the sample is composed of job stayers, i.e. workers who worked for no less than 12 months in both time $t$ and $t+1$ and who are aged no more than 54 (54+ workers are excluded to avoid mis-measurement due to retirement). We also exclude workers who change firm between two consecutive years, and/or job position within the same firm, so that y-o-y wage changes are not affected by changes in the characteristic of the job. With this sample selection we focus on quite stable workers: 95 per cent are employed with a permanent job contract, 5 per cent with a fixed-term ones, with a job duration longer than one year.

The central part of the Table refers instead to a sample which is further selected, to control for the potential source of (upward) bias, which could arise if, during the crisis, firms hire only those workers who are expected to have lower expected wage growth. We then focus only on workers already employed in the firm before $2007 .^{8}$

Last, it is possible that firms during the crisis preferred to retain only workers with lower expected wage growth, and fired the other ones. To control also for this possible source of selection, in the bottom part of the table we further select our sample by considering only workers who were continuously employed during the period 20082014.

As in Table 4 the first column reports the estimates of [7bis] with time fixed effects. The parameters $\delta_{1}$ and $\delta_{2}$ are then identified thanks to the province level variability. The estimates reported in the other two columns instead capture time trends by the use of inflation expectations and use two different estimators: OLS and GMM. In all the specifications and subsamples we find evidence of a steepening of the PC.

\footnotetext{
${ }^{8}$ The opposite case, i.e. that during the crisis firms prefer to hire workers with higher growth potential is would lead to a downward bias of our estimates, without significantly affect our conclusions.
} 
In Table 6 we further split the sample of job stayers into two: blue and white collars. If variable wage components allow firm to compress wage growth when unemployment is high, the PC relationship could vary also by type of worker, since typically the incidence of variable wages is higher for white collars than for blue collars. Here we find a negative relationship with no steepening for blue collars and a large steepening for white collars, confirming indirectly that the increased shape of the PC can be influenced by adjustments in the variable component of wages.

In Table 7 we re-run the estimates on job movers, defined as those who changed firm or job position or were not employed in the firm before 2008 or lost their job after 2008. All the results are confirmed.

We now consider a specific type of turnover, determined by job contract duration and we focus on fixed term workers (independently on the number of months worked in a year). Since each fixed-term worker can have more than one job spell within a year, for each temporary worker we calculate the percentage change in the average yearly daily wage. The estimates are reported in Table 8 and once again the estimates confirm the steepening of the PC after 2008, especially in the GMM specification, which supports the hypothesis of a strong increase in the slope of the PC in this segment (also when one considers the long-run effect). So, the increase of the slope of the PC can depend on composition effects, i.e. on and increase in the share of fixed term contracts in total workforce. However, since the steepening is found also for job stayers, we can conclude that composition effects are definitely not the only cause behind the steepening of the PC in Italy.

Last, for robustness we have also carried out some regressions (not reported) to check for further alternative specifications which could determine nonlinearities, like for instance higher elasticity of wages when unemployment increases than when it decreases. We have also checked whether the PC reacts to short run changes in unemployment $\left(\Delta U_{t}\right)$. The results do not support the existence of asymmetric response to unemployment, nor of a short run reaction of wages to changes in the unemployment rate.

As for firms, changes in workers' compositions are unlikely to be the (only) cause of the steepening of the PC in Italy after 2008. 


\section{Conclusions}

The behavior of inflation in advanced economies during and after the global financial crisis has sparked renewed interest in the Phillips curve. The so-called twin puzzle of missing disinflation in the aftermath of the global financial crisis and persistently low inflation in spite of the ongoing recovery in the euro area following the sovereign debt crisis have led many to rethink about the Phillips curve. While most of the literature has focused on the relationship between consumer' price inflation and economic slack, in this paper we look at wage inflation for two important reasons. First there is evidence that in the euro area domestic factors played an important role besides global disinflationary forces. Second, in several euro area countries labor markets have gone through some modification following the globalization process, the monetary union and more recently the double dip recession. In particular, the interaction of a deep and prolonged crisis with policy reforms raises the question whether parameter instability and or non-linearities might shape the response of wages to the unemployment rate. We tackle these issues from a variety of angles, using both macro time series models and micro panel data (for Italy only). We find evidence that the wage Phillips curve has changed since the Great financial crisis. In particular we find evidence of an increased correlation between wage inflation and the unemployment rate in Italy, France and Spain while such correlation has diminished in Germany. For Italy, this macro evidence is supported also by microeconometric evidence. We then try to uncover some of the factors behind it and suggest two explanations. One refers to the increased pro-cyclicality of incumbent wages, through the increasing use of flexible wage schemes, the other refers to the increased use of fixed-term contracts which by their own nature leads to higher frequency of re-setting wages, a phenomenon that mirrors the higher frequency of price adjustment recorded among Italian firms after the Great financial crisis (Fabiani and Porqueddu 2014) and put forward as an explanation of the increased responsiveness of price inflation to economic slack. Our results are robust to a variety of controls and in particular to changes over the business cycle in the composition of the universe of firms (due to entry and exit phenomena) and of the workforce. 


\section{References}

Adamopoulou E., E. Bobbio, M. De Philippis e F. Giorgi, (2016a) "Wage rigidities and business cycle fluctuations: A linked employer-employee analysis", Bank of Italy, (mimeo).

Adamopoulou E. , E. Bobbio, M. De Philippis e F. Giorgi, (2016a), "Allocative efficiency and aggregate wage dynamics in Italy, 1990-2013", Bank of Italy, (mimeo).

Anderton R. and Bonthuis B. (2015) "Downward Wage Rigidities in the Euro Area" University of Nottingham, Research paper series.

Borio, C. E. V., and A. Filardo. 2007. "Globalisation and Inflation: New Cross-Country Evidence on the Global Determinants of Domestic Inflation." BIS Working Paper No. 227.

Babecký, J., P. Du Caju, T. Kosma, M. Lawless, J. Messina and T. Rõõm (2009), "The margins of labour cost adjustments: Survey Evidence from European Firms", ECB Working Paper, No.1164.

Blanchard O. (2016) “The Phillips Curve: Back to the '60s?", American Economic Review: Papers \& Proceedings, 106(5): 31-34.

Bryson A., Freeman R., Lucifora C., Pellizzari M. and Perotin V. (2012) "Paying For Performance: Incentive Pay Schemes and Employees' Financial Participation", CEP discussion paper, no. 1112.

Bodo, G. and Sestito, P. (1994) "Squilibri territoriali nel mercato del lavoro e inflazione", in C. Dell'Aringa, Caratteri strutturali dell'inflazione italiana, Il Mulino: Bologna.

Clark, P.B., Laxton, D., Rose, D., (1996). Asymmetry in the U.S. output-inflation nexus: Issues and evidence, IMF Staff, Paper 43, International Monetary Fund, Washington.

Coibion O. and Gorodnichenko Y., (2015) "Is the Phillips Curve Alive and Well after All? Inflation Expectations and the Missing Disinflation", American Economic Journal: Macroeconomics, vol. 7(1), pages 197-232, January.

Daly M. C. and Hobijn B. (2014) "Downward Nominal Wage Rigidities Bend the Phillips Curve", Federal Reserve Bank of San Francisco, Working Paper.

Eurofound (2001) Variable pay in Europe, http://www.eurofound.europa.eu/observatories/eurwork/comparativeinformation/variable-pay-in-europe.

Fabiani S. and Porqueddu M., (2014) 'E' aumentata la flessibilità nominale negli ultimi anni? Evidenze per l'Italia sui prezzi al consumo" in "Gli effetti della crisi sul potenziale produttivo e sulla spesa delle famiglie in Italia", Banca d'Italia, Seminari e Convegni.

Galì J. (2010), “The return of the wage Phillips curve” NBER Working Paper n.15758. 
Gaiotti E. (2010) "Has Globalization Changed the Phillips Curve? Firm-Level Evidence on the Effect of Activity on Prices", International Journal of Central Banking, 51-84.

Giannone, D., Lenza, M., Momferatou, D., and Onorante, L. (2014), "Short-term inflation projections: A Bayesian vector autoregressive approach", International Journal of Forecasting, 30(3), 635-644.

Giraitis L., Kapetanios G. and Price S. (2013), "Adaptive forecasting in the presence of recent and ongoing structural change", Journal of Econometrics, 177, 153-170.

Giraitis L., Kapetanios G. and Yates A. (2014), "Inference on stochastic time varying coefficient models", Journal of Econometrics, 179, 46-65.

Gregg P., Machin S. and M. Fernandez-Salgado (2014) "Real wages and unemployment in the big squeeze", The Economic Journal, 124 (May), 408-432.

Hnatkovska V. and Loayza, N. (2005), "Volatility and Growth", in Managing Economic Volatility and Crises: A Practitioner's Guide. Cambridge: Cambridge University Press, 65-100.

IMF, (2013): “The Dog That Didn't Bark: Has Inflation Been Muzzled or Was It Just Sleeping?" World Economic Outlook, International Monetary Fund.

Jimeno, J.F., M. Izquierdo, A. Lamo, S. Millard, T. Rööm, E. Viviano, and D. Kosma (2016) "Labour market adjustments in Europe during the crisis: Microeconomic evidence from the Wage Dynamics Network Survey", ECB, (mimeo).

Judson R. and Orphanides, A. (1999), "Inflation, Volatility, and Growth", International Finance, 2, 117-138.

Mullineaux D. J. (1980), "Unemployment, Industrial Production, and Inflation Uncertainty in the United States", The Review of Economics and Statistics, 62(2), 163169.

Pissarides C. (2009), "The unemployment volatility puzzle", Econometrica, 77(5), 1339-1369.

Riggi M. and Venditti F. (2015), "Failing to forecast low inflation and Phillips curve instability: a euro area perspective", International Finance, Volume 18, Issue 1, Pages 47-68.

Rosolia A. (2015) "On the response of Italian wages to the unemployment rate", Banca d'Italia, Questioni di economia e finanza, n. 287.

Sestito P. (1994) "Determinazione del Salario in Italia: una Rassegna della Letteratura Empirica , un'Analisi della Letteratura Macro," in C. Dell'Aringa, ed., La Determinazione dei Salari: Teoria ed Evidenza Empirica, Economia del lavoro, Napoli: Edizioni Scientifiche, Italiane, 1994.

Visco I. (1984) "Inflation Expectations: The use of Italian survey data in the analysis of their formation and effects on wage changes", OECD working paper. 


\section{Tables and figures}

Table 1: Euro area, years 2010-13: probability to adjust wages and unemployment rate Dependent variables: probabilities to freeze/cut base and variable wages.

\begin{tabular}{llll}
\hline & $\begin{array}{l}\text { Base wage } \\
\text { freeze }\end{array}$ & $\begin{array}{l}\text { Base wage } \\
\text { cut }\end{array}$ & $\begin{array}{l}\text { Variable } \\
\text { wage cut }\end{array}$ \\
\hline Unemployment rate & 0.9 & 0.3 & 0.8 \\
& $(0.000)^{* * *}$ & $(0.000)^{* * *}$ & $(0.000)^{* * *}$ \\
Year dummies & yes & yes & yes \\
Firm fixed effects & yes & yes & yes \\
Observations & 62820 & 62820 & 61108 \\
R-squared & 0.309 & 0.161 & 0.443 \\
Average (pp) & 11.3 & 1.6 & 12.6 \\
\hline $\begin{array}{l}\text { Robust } p \text { values in parentheses; } \\
\text { significant at } 1 \% \text {. WDN thificant at }\end{array}$ & $10 \% ;{ }^{* *}$ significant at 5\%; ${ }^{* * *}$ \\
\hline
\end{tabular}

Table 2: End of sample instability test (equation 2)

\begin{tabular}{lllll}
\hline & Italy & France & Germany & Spain \\
\hline & All & & & \\
parameters & & & \\
Sup-L(.75) & 1 & 0 & 1 & .6 \\
Sup-L(.90) & 1 & 0 & 1 & .6 \\
Exp-L(.75) & 1 & 0 & 1 & .4 \\
Exp-L(.90) & 1 & 0 & 1 & .6 \\
Sup-L(.01-.99) & 1 & 0 & 1 & .6 \\
Exp-L(.01-.99) & 1 & 0 & 1 & .6 \\
& Single & & & \\
Sup-L(.75) & parameter & & & .6 \\
Sup-L(.90) & 1 & 0 & 1 & .6 \\
Exp-L(.75) & 1 & 0 & 1 & .6 \\
Exp-L(.90) & 1 & 0 & 1 & .6 \\
Sup-L(.01-.99) & 1 & 0 & 1 & .6 \\
Exp-L(.01-.99) & 1 & 0 & 1 & .6 \\
\hline Values reported & 1 & .2 & 1 & \\
\hline
\end{tabular}

Values reported are the average across $h=0, \ldots, 4$ where the result of the test is coded with 1 if the test rejects at the 10\% the null hypothesis of constant parameters in favor of time varying parameters, with 0 if the null hypothesis of constant parameters cannot be rejected at the $10 \%$ 
Table 3: End of sample instability test (equation 6)

\begin{tabular}{lllll}
\hline & Italy & France & Germany & Spain \\
\hline & All & & & \\
& parameters & & & \\
Sup-L(.75) & 1 & 1 & 1 & .4 \\
Sup-L(.90) & 1 & 1 & 1 & .4 \\
Exp-L(.75) & 1 & 1 & 1 & .4 \\
Exp-L(.90) & 1 & 1 & 1 & .4 \\
Sup-L(.01-.99) & 1 & 1 & 1 & .4 \\
Exp-L(.01-.99) & 1 & 1 & 1 & \\
& Single & & & .4 \\
Sup-L(.75) & parameter & & & .4 \\
Sup-L(.90) & 1 & 1 & 1 & .4 \\
Exp-L(.75) & 1 & 1 & 1 & .4 \\
Exp-L(.90) & 1 & 1 & 1 & .4 \\
Sup-L(.01-.99) & 1 & 1 & 1 & \\
Exp-L(.01-.99) & 1 & 1 & 1 & \\
\hline Values reported are the average across $h=0, \ldots, 4$ where the result of the test is coded with \\
1 if the test rejects at the 10\% the null hypothesis of constant parameters in favor of time \\
varying parameters, with & 0 if the null hypothesis of constant parameters cannot be \\
rejected at the 10\%. & \multicolumn{5}{l}{}
\end{tabular}


Table 4: Wage Phillips curve in Italy: Firm-level estimates (p-values in brackets). Dependent variable: percentage change in the annual average wage per worker.

\begin{tabular}{|c|c|c|c|}
\hline & OLS & OLS & GMM \\
\hline & \multicolumn{3}{|l|}{ All firms } \\
\hline \multirow[t]{2}{*}{$\Delta w_{t-1}$} & -0.00006 & -0.00006 & 0.274 \\
\hline & $(0.152)$ & $(0.155)$ & $(0.000)^{* * *}$ \\
\hline \multirow[t]{2}{*}{$U_{t}$} & -0.00015 & -0.225 & -0.169 \\
\hline & $(0.972)$ & $(0.000)^{* * *}$ & $(0.000)^{* * *}$ \\
\hline \multirow[t]{2}{*}{$U_{t} * D_{\text {post } 2008}$} & -0.006 & -0.066 & -0.083 \\
\hline & $(0.014)^{* *}$ & $(0.000)^{* * *}$ & $(0.000)^{* * *}$ \\
\hline \multirow{2}{*}{$E_{t} \Delta p_{t+1}$} & & 0.004 & 0.006 \\
\hline & & $(0.000)^{* * *}$ & $(0.000)^{* * *}$ \\
\hline Year dummies & yes & no & no \\
\hline Firm fixed effects & yes & yes & yes \\
\hline Observations & $1.21 \mathrm{E}+07$ & $1.21 \mathrm{E}+07$ & $1.15 \mathrm{E}+07$ \\
\hline \multirow[t]{2}{*}{ Number of firms } & 2474469 & 2474469 & 2381249 \\
\hline & \multicolumn{3}{|c|}{ All firms (already operating before '08) } \\
\hline \multirow{2}{*}{$\Delta w_{t-1}$} & -0.0004 & -0.0004 & 0.334 \\
\hline & $(0.002)^{* * *}$ & $(0.002)^{* * *}$ & $(0.000)^{* * *}$ \\
\hline \multirow[t]{2}{*}{$U_{t}$} & 0.001 & -0.223 & -0.18 \\
\hline & $(0.775)$ & $(0.000)^{* * *}$ & $(0.000)^{* * *}$ \\
\hline \multirow{2}{*}{$U_{t} * D_{\text {post } 2008}$} & -0.006 & -0.065 & -0.082 \\
\hline & $(0.016)^{* *}$ & $(0.000)^{* * *}$ & $(0.000)^{* * *}$ \\
\hline \multirow[t]{2}{*}{$E_{t} \Delta p_{t+1}$} & & 0.006 & 0.008 \\
\hline & & $(0.000)^{* * *}$ & $(0.000)^{* * *}$ \\
\hline Year dummies & yes & no & no \\
\hline Firm fixed effects & yes & yes & yes \\
\hline Observations & $1.04 \mathrm{E}+07$ & $1.04 \mathrm{E}+07$ & 9987063 \\
\hline \multirow[t]{2}{*}{ Number of firms } & 1760753 & 1760753 & 1729694 \\
\hline & \multicolumn{3}{|c|}{ All firms (already operating before ' $08+$ present until '13) } \\
\hline \multirow[t]{2}{*}{$\Delta w_{t-1}$} & -0.002 & -0.002 & 0.200 \\
\hline & $(0.045)^{* *}$ & $(0.045)^{* *}$ & $(0.000)^{* * *}$ \\
\hline \multirow[t]{2}{*}{$U_{t}$} & 0.004 & -0.301 & -0.230 \\
\hline & $(0.432)$ & $(0.000)^{* * *}$ & $(0.000)^{* * *}$ \\
\hline \multirow[t]{2}{*}{$U_{t} * D_{\text {post } 2008}$} & -0.009 & -0.053 & -0.082 \\
\hline & $(0.000)^{* * *}$ & $(0.000)^{* * *}$ & $(0.000)^{* * *}$ \\
\hline \multirow{2}{*}{$E_{t} \Delta p_{t+1}$} & & 0.005 & 0.006 \\
\hline & & $(0.000)^{* * *}$ & $(0.000)^{* * *}$ \\
\hline Year dummies & yes & no & no \\
\hline Firm fixed effects & yes & yes & yes \\
\hline Observations & 6414023 & 6414023 & 6354583 \\
\hline Number of firms & 750235 & 750235 & 750235 \\
\hline
\end{tabular}


Table 5: Wage Phillips curve in Italy: Individual estimates; Job stayers (p-values in brackets). Dependent variable: percentage change in the daily wage.

\begin{tabular}{|c|c|c|c|}
\hline & OLS & OLS & GMM \\
\hline & \multicolumn{3}{|c|}{ All workers (employed at both time $t$ and $t+1$ ) } \\
\hline \multirow{2}{*}{$\Delta w_{t-1}$} & -0.211 & -0.205 & 0.077 \\
\hline & $(0.000)^{* * *}$ & $(0.000)^{* * *}$ & $(0.000)^{* * *}$ \\
\hline \multirow[t]{2}{*}{$U_{t}$} & 0.005 & -0.417 & -0.178 \\
\hline & $(0.461)$ & $(0.000)^{* * *}$ & $(0.000)^{* * *}$ \\
\hline \multirow[t]{2}{*}{$U_{t} * D_{\text {post } 2008}$} & -0.008 & -0.063 & -0.072 \\
\hline & $(0.053)^{*}$ & $(0.000)^{* * *}$ & $(0.000)^{* * *}$ \\
\hline \multirow[t]{2}{*}{$E_{t} \Delta p_{t+1}$} & & 0.010 & 0.009 \\
\hline & & $(0.000)^{* * *}$ & $(0.000)^{* * *}$ \\
\hline Year dummies & yes & no & no \\
\hline Firm fixed effects & yes & yes & yes \\
\hline Observations & 3588786 & 3588786 & 3173763 \\
\hline \multirow[t]{2}{*}{ Number of firms } & 683357 & 683357 & 648836 \\
\hline & \multicolumn{3}{|c|}{$\begin{array}{l}\text { All workers (already employed before ' } 08 \text {; same firm, not } \\
\text { changing position from } t \text { to } t+1 \text { ) }\end{array}$} \\
\hline \multirow[t]{2}{*}{$\Delta w_{t-1}$} & -0.186 & -0.181 & 0.082 \\
\hline & $(0.000)^{* * *}$ & $(0.000)^{* * *}$ & $(0.000)^{* * *}$ \\
\hline \multirow[t]{2}{*}{$U_{t}$} & -0.003 & -0.318 & -0.178 \\
\hline & (0.595) & $(0.000)^{* * *}$ & $(0.000)^{* * *}$ \\
\hline \multirow[t]{2}{*}{$U_{t} * D_{\text {post } 2008}$} & -0.007 & -0.061 & -0.078 \\
\hline & $(0.082)^{*}$ & $(0.000)^{* * *}$ & $(0.000)^{* * *}$ \\
\hline \multirow[t]{2}{*}{$E_{t} \Delta p_{t+1}$} & & 0.010 & 0.010 \\
\hline & & $(0.000)^{* * *}$ & $(0.000)^{* * *}$ \\
\hline Year dummies & yes & no & no \\
\hline Firm fixed effects & yes & yes & yes \\
\hline Observations & 2585290 & 2585290 & 2460382 \\
\hline \multirow[t]{2}{*}{ Number of firms } & 507951 & 507951 & 497330 \\
\hline & \multicolumn{3}{|c|}{$\begin{array}{l}\text { All workers (already employed before ' } 08 \text { and working } \\
\text { until '14; same firm, not changing position from t to } t+1 \text { ) }\end{array}$} \\
\hline \multirow[t]{2}{*}{$\Delta w_{t-1}$} & -0.189 & -0.18 & 0.109 \\
\hline & $(0.000)^{* * *}$ & $(0.000)^{* * *}$ & $(0.000)^{* * *}$ \\
\hline \multirow[t]{2}{*}{$U_{t}$} & -0.023 & -0.367 & -0.204 \\
\hline & $(0.004)^{* * *}$ & $(0.000)^{* * *}$ & $(0.000)^{* * *}$ \\
\hline \multirow[t]{2}{*}{$U_{t} * D_{\text {post } 2008}$} & 0.002 & -0.039 & -0.055 \\
\hline & $(0.780)$ & $(0.000)^{* * *}$ & $(0.000)^{* * *}$ \\
\hline \multirow[t]{2}{*}{$E_{t} \Delta p_{t+1}$} & & 0.009 & 0.009 \\
\hline & & $(0.000)^{* * *}$ & $(0.000)^{* * *}$ \\
\hline Year dummies & yes & no & no \\
\hline Firm fixed effects & yes & yes & yes \\
\hline Observations & 1063247 & 1063247 & 1057311 \\
\hline Number of firms & 132092 & 132092 & 132015 \\
\hline
\end{tabular}


Table 6: Wage Phillips curve in Italy: Individual estimates - Job Stayers - Blue and white collars (p-values in brackets). GMM estimates. Dependent variable: percentage change in the daily wage.

\begin{tabular}{lll}
\hline & White collars & Blue collars \\
& & \\
$\Delta w_{t-1}$ & 0.111 & 0.065 \\
& $(0.000)^{* * *}$ & $(0.000)^{* * *}$ \\
$U_{t}$ & -0.15 & -0.243 \\
& $(0.000)^{* * *}$ & $(0.000)^{* * *}$ \\
$U_{t} * D_{\text {post } 2008}$ & -0.121 & -0.003 \\
& $(0.000)^{* * *}$ & $(0.767)$ \\
$E_{t} \Delta p_{t+1}$ & 0.009 & 0.008 \\
& $(0.000)^{* * *}$ & $(0.000)^{* * *}$ \\
Year dummies & yes & no \\
Individual fixed effects & yes & yes \\
Observations & 101185 & 62486 \\
Number of workers & 687536 & 496136 \\
\hline Robust $p$ values in parentheses; ${ }^{*}$ significant. at $10 \% ;{ }^{* *}$ at $5 \% ;{ }^{* * *}$ at \\
1\%.
\end{tabular}

Table 7: Wage Phillips curve in Italy: Individual estimates - Job movers (p-values in brackets). Dependent variable: percentage change in the daily wage.

\begin{tabular}{llll}
\hline & OLS & OLS & GMM \\
$\Delta w_{t-1}$ & -0.218 & -0.212 & 0.065 \\
$U_{t}$ & $(0.000)^{* * *}$ & $(0.000)^{* * *}$ & $(0.000)^{* * *}$ \\
& 0.019 & -0.412 & -0.152 \\
$U_{t} * D_{\text {post2008 }}$ & $(0.017)^{* *}$ & $(0.000)^{* * *}$ & $(0.000)^{* * *}$ \\
& -0.012 & -0.087 & -0.073 \\
$E_{t} \Delta p_{t+1}$ & $(0.042)^{* *}$ & $(0.000)^{* * *}$ & $(0.000)^{* * *}$ \\
& & 0.009 & 0.010 \\
Year dummies & & $(0.000)^{* * *}$ & $(0.000)^{* * *}$ \\
Individual fixed effects & yes & no & no \\
Observations & $2,525,539$ & yes & yes \\
Number of workers & 610,333 & $2,525,539$ & $2,116,452$ \\
\multicolumn{2}{l}{ Robust $p$ values in parentheses; ${ }^{*}$ significant. at $10 \% ; * *$ at $5 \% ; * * *$ at $1 \% .}$. \\
\hline
\end{tabular}


Table 8: Wage Phillips curve in Italy: Individual estimates - Fixed term workers (pvalues in brackets). Dependent variable: percentage change in the average daily wage.

OLS

$$
\Delta w_{t-1}
$$

$U_{t}$

$U_{t} * D_{\text {post2008 }}$

$E_{t} \Delta p_{t+1}$

Year dummies

Individual fixed effects

Observations

Number of workers
OLS

$\begin{array}{ll}-0.048 & 0.260 \\ (0.000)^{* * *} & (0.000)^{* * *} \\ -0.067 & -0.014 \\ (0.000)^{* * *} & (0.858) \\ -0.058 & -0.304 \\ (0.001)^{* * *} & (0.000)^{* * *} \\ 0.005 & 0.009 \\ (0.000)^{* * *} & (0.000)^{* * *} \\ \text { no } & \text { no } \\ \text { yes } & \text { yes } \\ 419,922 & 419,922 \\ 192,702 & 192,702\end{array}$

Robust $\mathrm{p}$ values in parentheses; ${ }^{*}$ significant. at $10 \%$; ${ }^{* *}$ at $5 \%$; ${ }^{* * *}$ at $1 \%$. Since fixed term workers can have more than 1 job spell within a year the dependent variable is the percentage difference between the average daily wages in two consecutive years. 
Figure 1: Euro area, 19 countries. Nominal wage growth and unemployment.

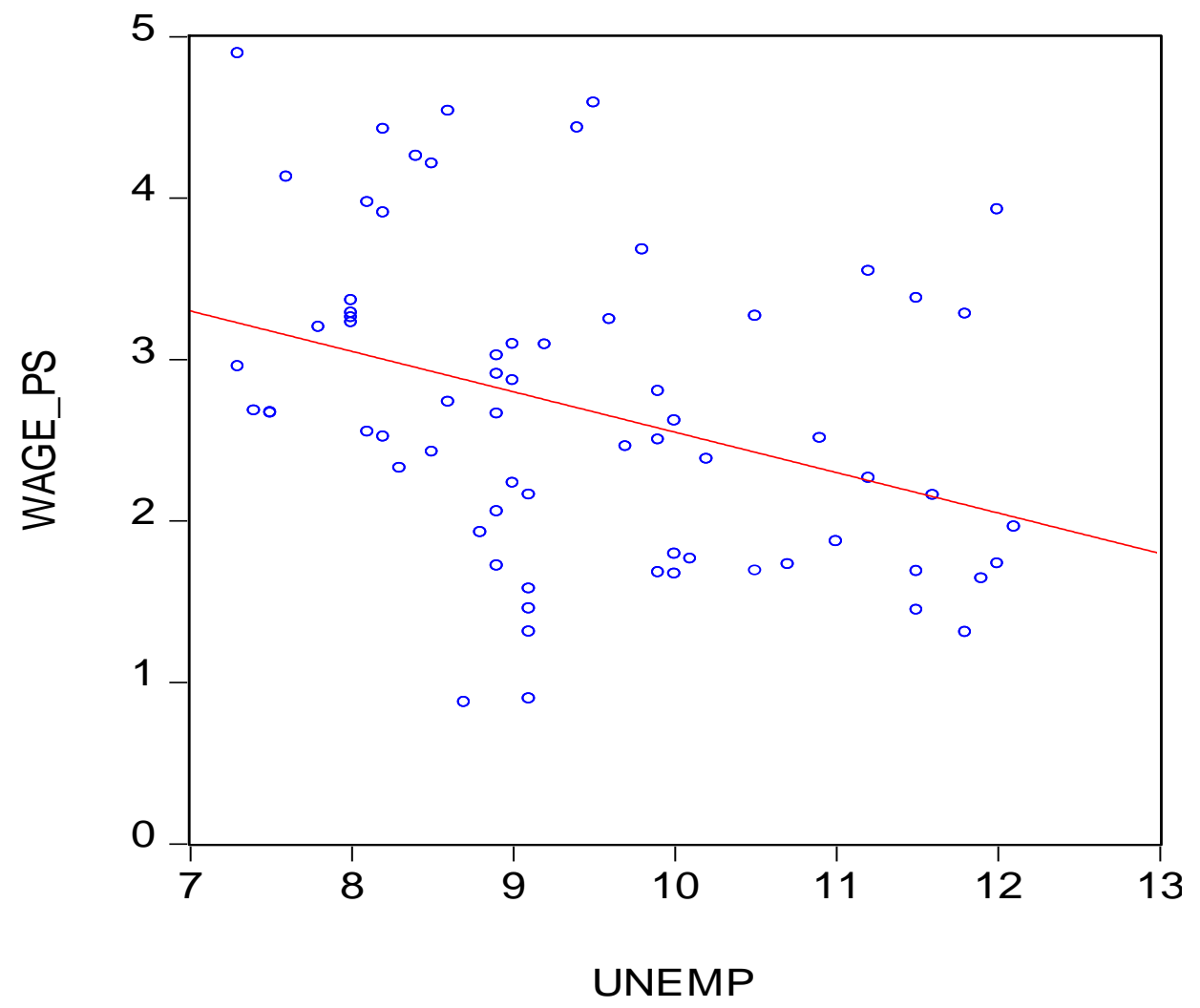

Eurostat data. 
Figure 2: Phillips curve expanding window regressions euro area

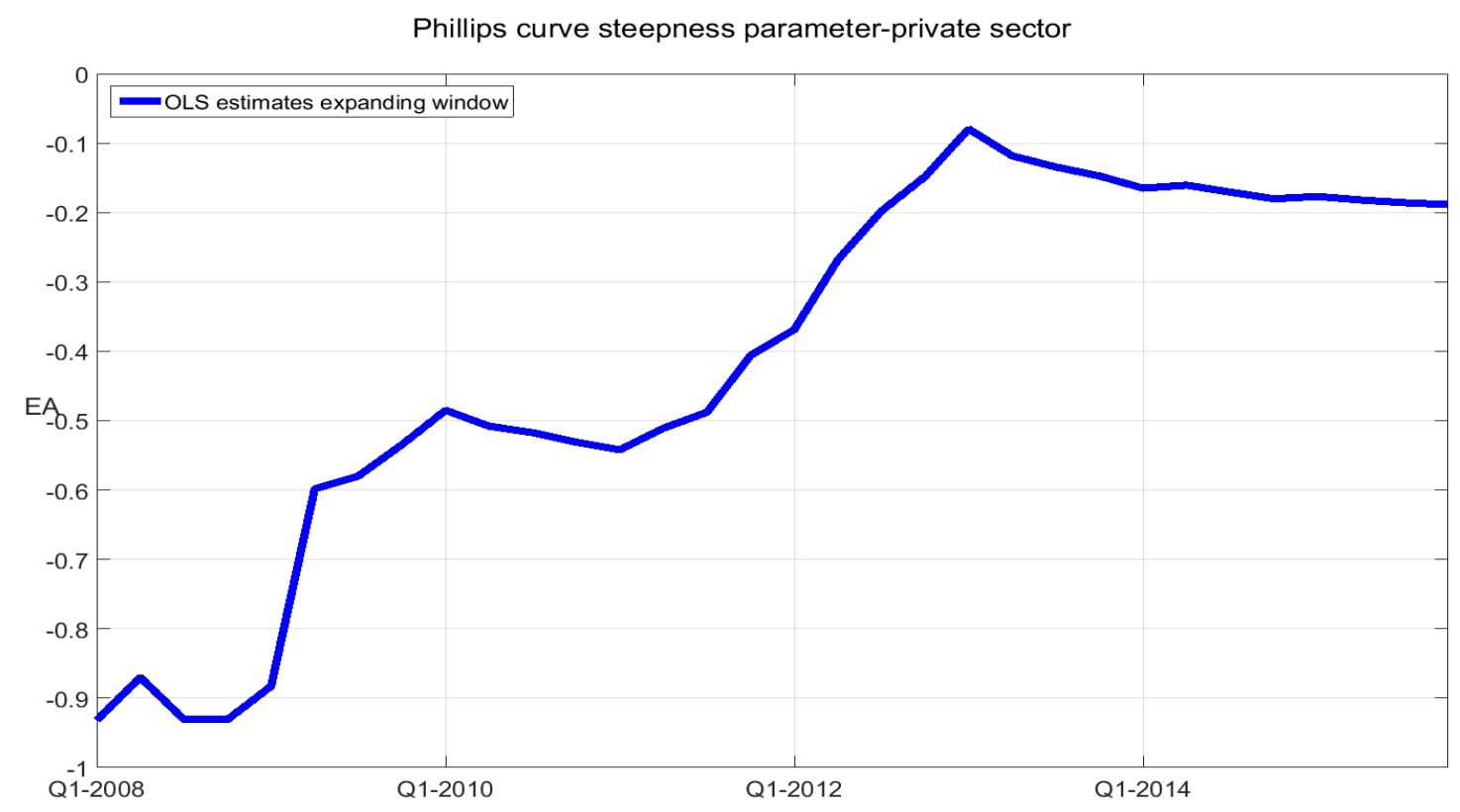

The blue lines show the OLS estimates of the parameter of unemployment rate for different samples: the first point refers to the sample 1999Q1-2008Q1 the last point refers to the sample 1999Q1-2015Q4. 
Figure 3: Phillips curve expanding window regressions euro area countries
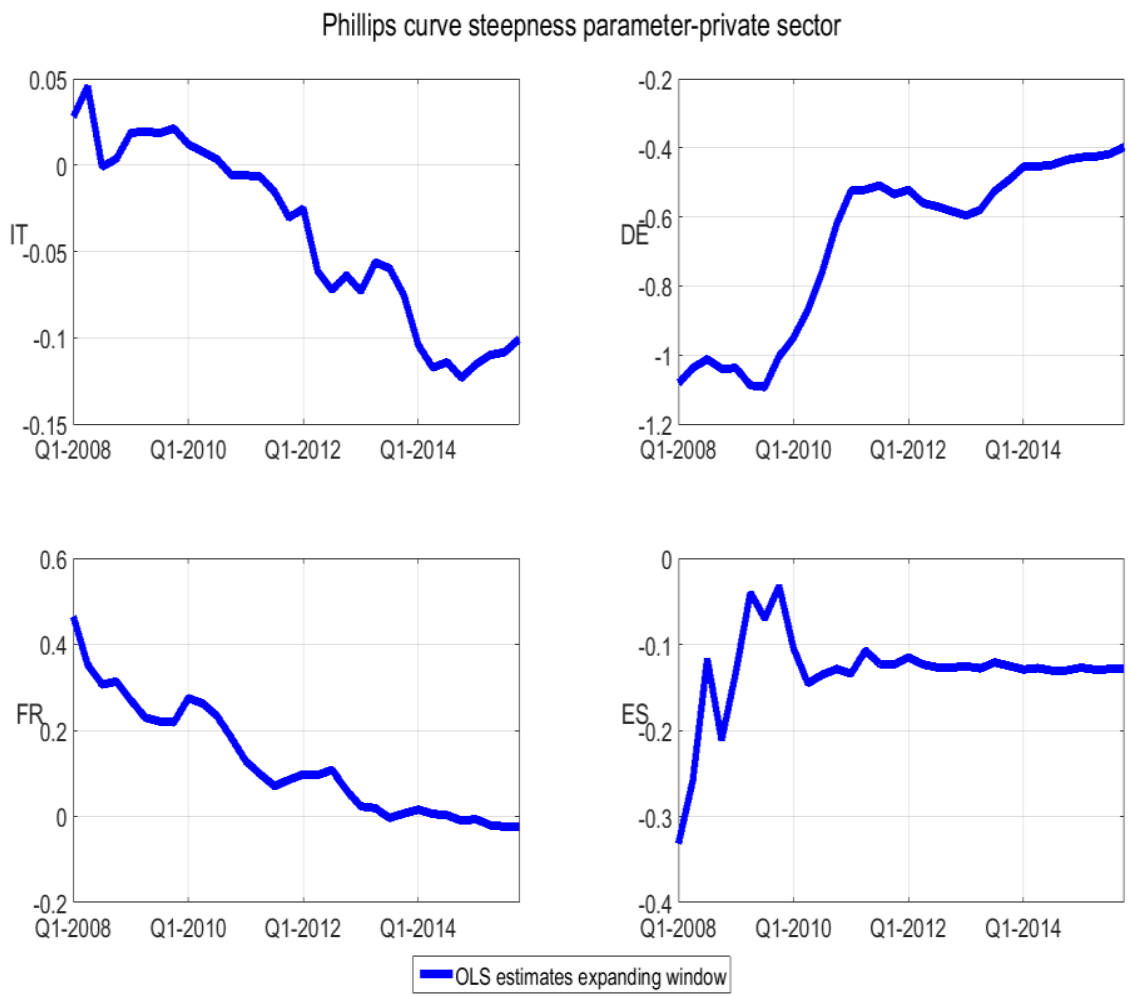

The blue lines show the OLS estimates of the parameter of unemployment rate for different samples: the first point refers to the sample 1999Q1-2008Q1 the last point refers to the sample 1999Q1-2015Q4. 
Figure 4: Country specific evidence of instability of the unemployment parameter in Wage Phillips Curve

(a) $\Delta^{4} w_{t}=c_{t}+\sum_{i=1}^{h} \beta_{i t} \Delta^{4} w_{t-i}+\delta_{t} E_{t} \Delta p_{t+1}+\gamma_{t} U_{t}+\varepsilon_{t}$

Phillips curve steepness parameter-private sector
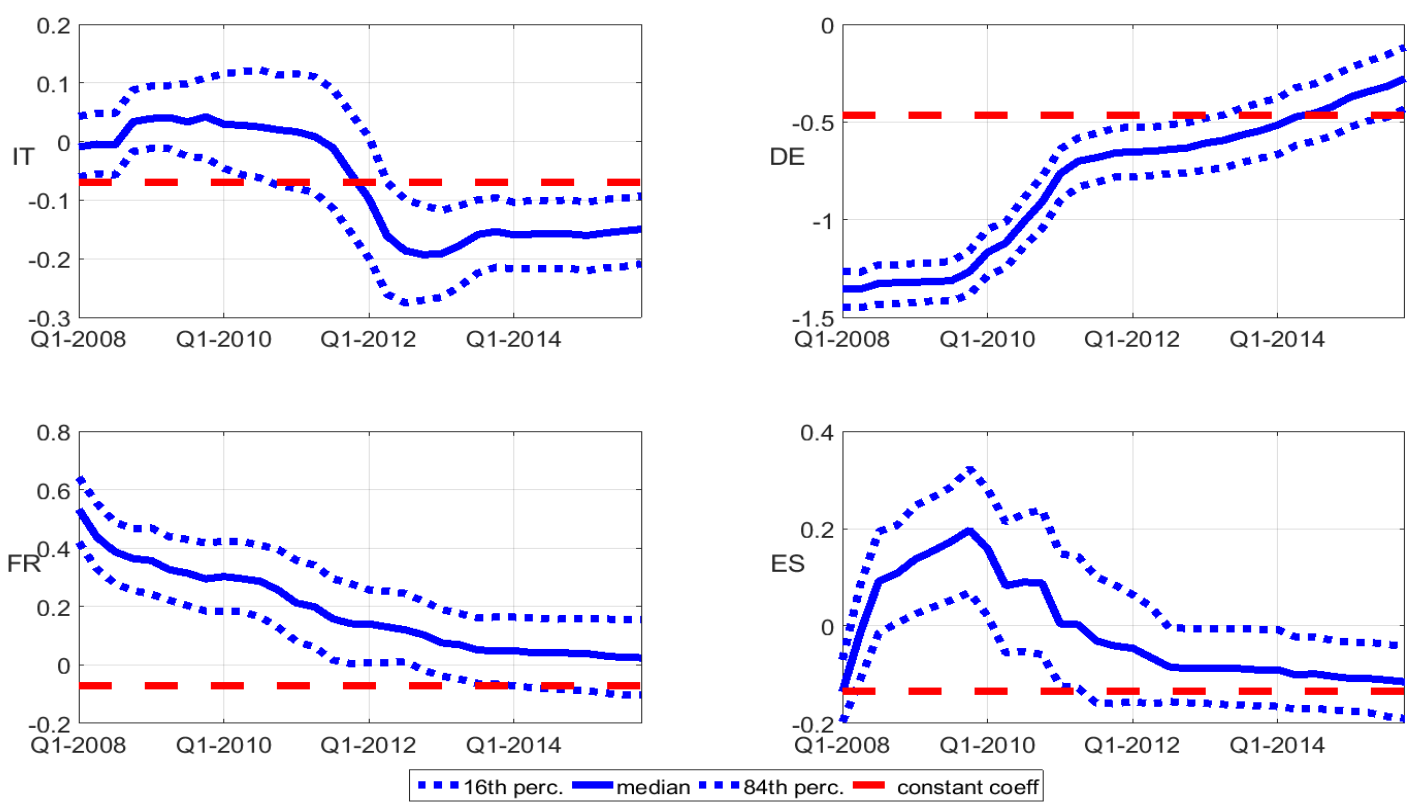

(b) $\Delta^{4} w_{t}=c_{t}+\sum_{i=1}^{h} \beta_{i t} \Delta^{4} p_{t-i}+\delta_{t} E_{t} \Delta p_{t+1}+\gamma_{t} U_{t}+\varepsilon_{t}$

Phillips curve steepness parameter-private sector
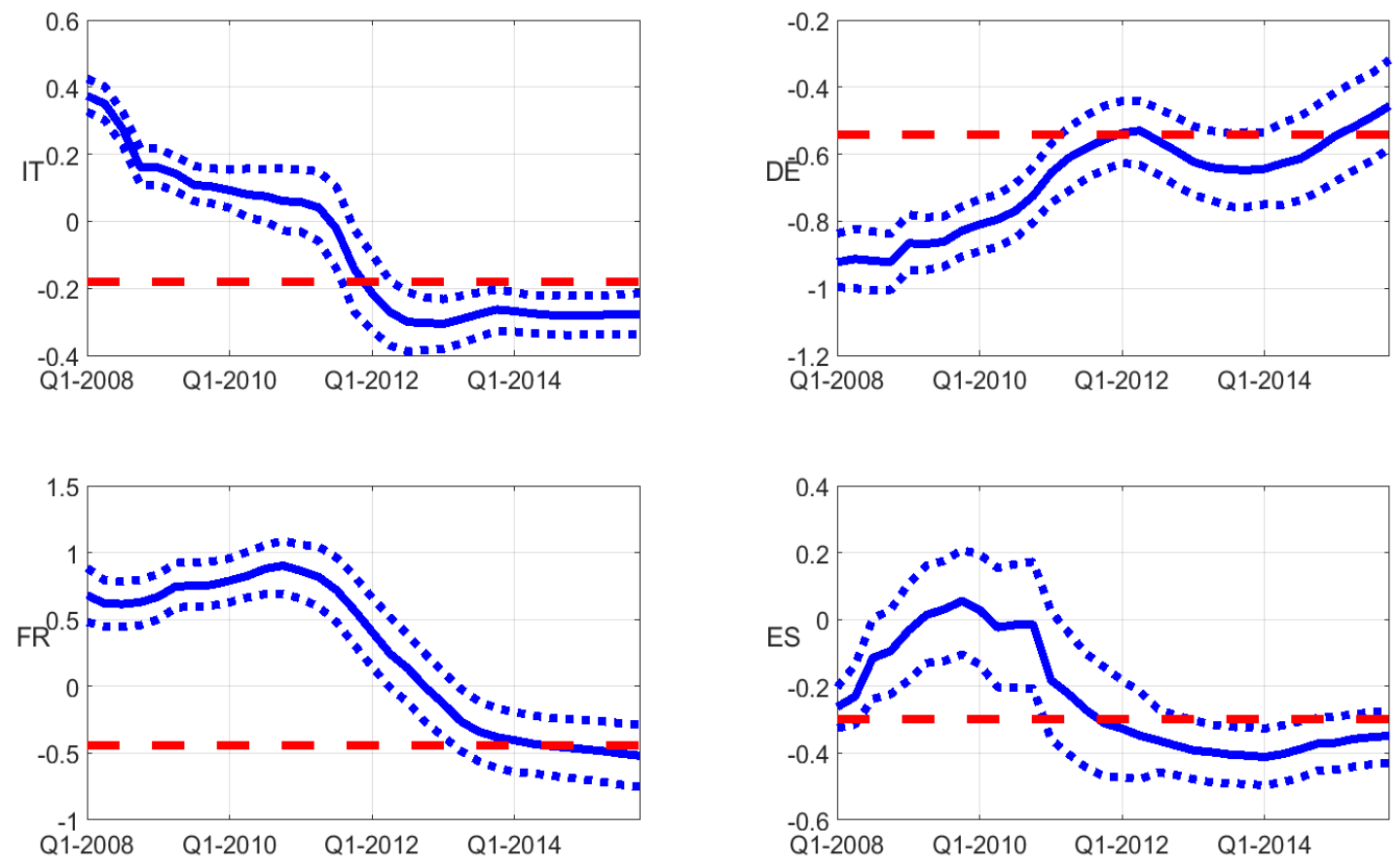

- " 16th perc. $=$ median $~ " ~-84$ th perc. $=$ constant coeff

The blue lines are 16th 50th and 84th percentile from time varying parameter model. The red line is OLS estimate from constant parameter model estimated over period 1999Q1-2015Q4 
Figure 5: Sector specific evidence of instability of the unemployment parameter in Wage Phillips Curve

(a) $\Delta^{4} w_{t}=c_{t}+\sum_{i=1}^{h} \beta_{i t} \Delta^{4} w_{t-i}+\delta_{t} E_{t} \Delta p_{t+1}+\gamma_{t} U_{t}+\varepsilon_{t}$

Phillips curve steepness parameter-private sector
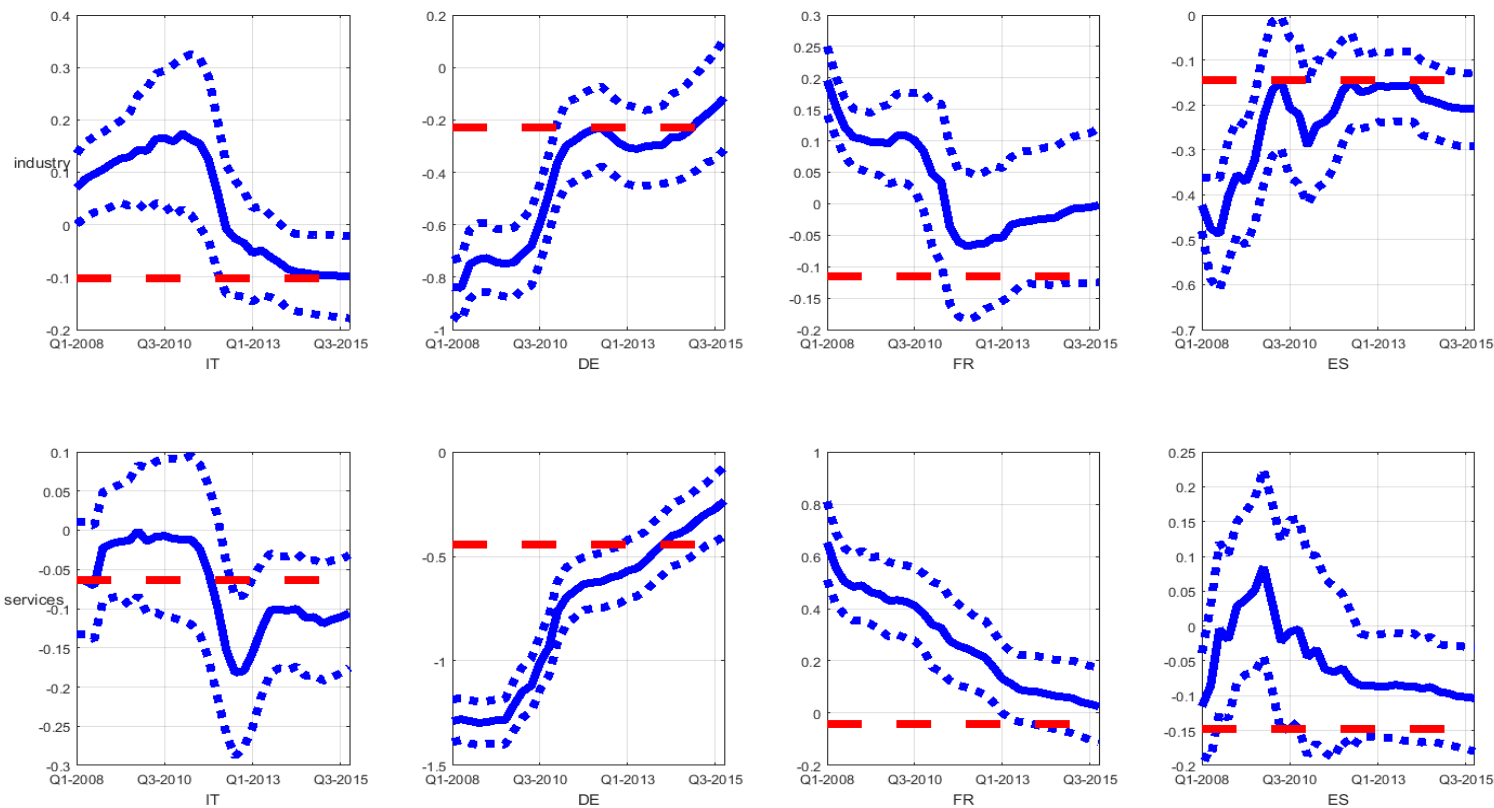

(b) $\Delta^{4} w_{t}=c_{t}+\sum_{i=1}^{h} \beta_{i t} \Delta^{4} p_{t-i}+\delta_{t} E_{t} \Delta p_{t+1}+\gamma_{t} U_{t}+\varepsilon_{t}$

Phillips curve steepness parameter-private sector
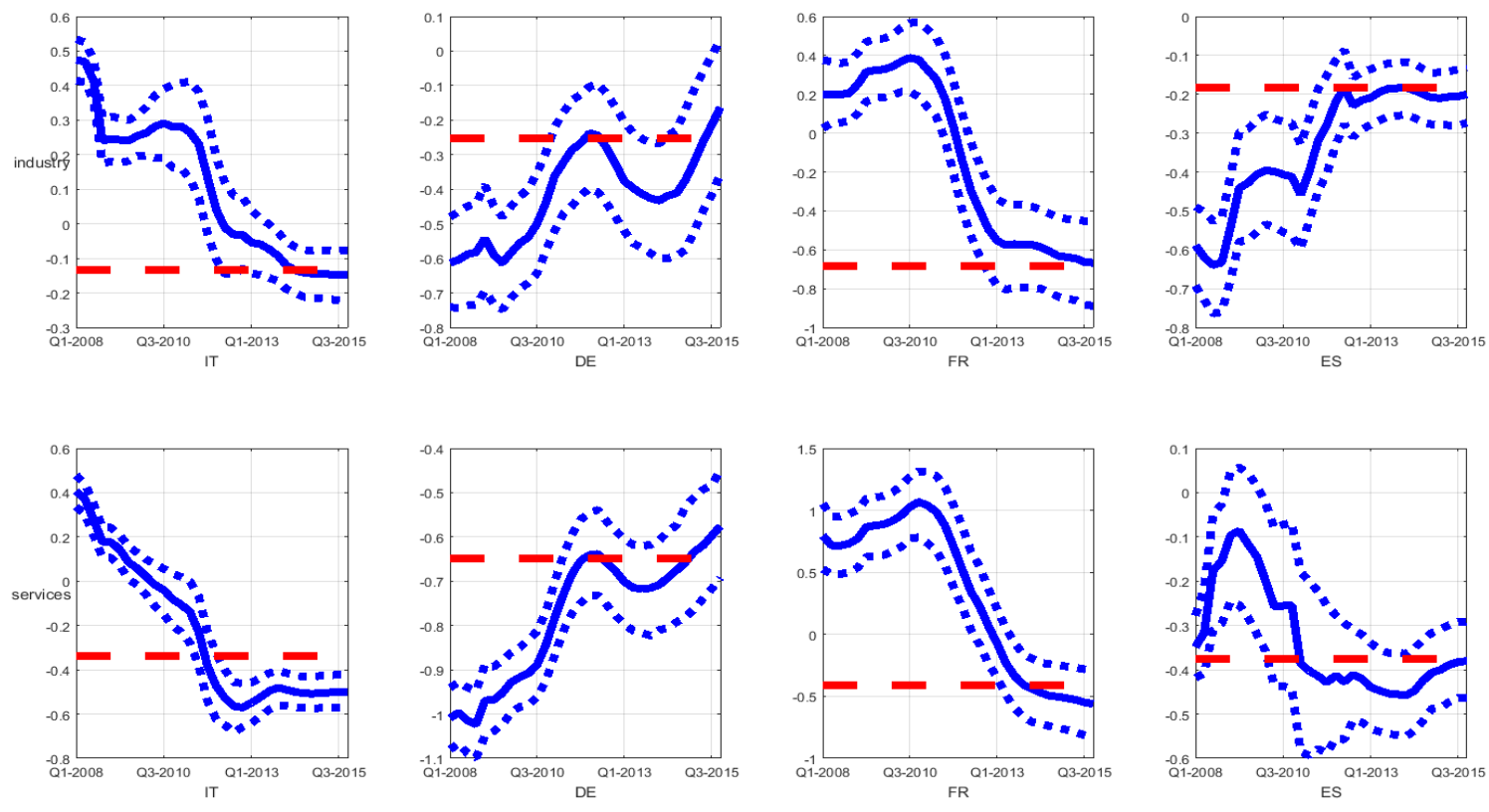

(1) Blue lines are 16th 50th and 84th percentile from time varying parameter model. The red line is OLS estimate from constant parameter model estimated over period 1999Q1-2015Q4 
Figure 6: Robustness to discounting factor

$$
\Delta^{4} w_{t}=c_{t}+\sum_{i=1}^{h} \beta_{i t} \Delta^{4} w_{t-i}+\delta_{t} E_{t} \Delta p_{t+1}+\gamma_{t} U_{t}+\varepsilon_{t}
$$

Phillips curve steepness parameter-private sector
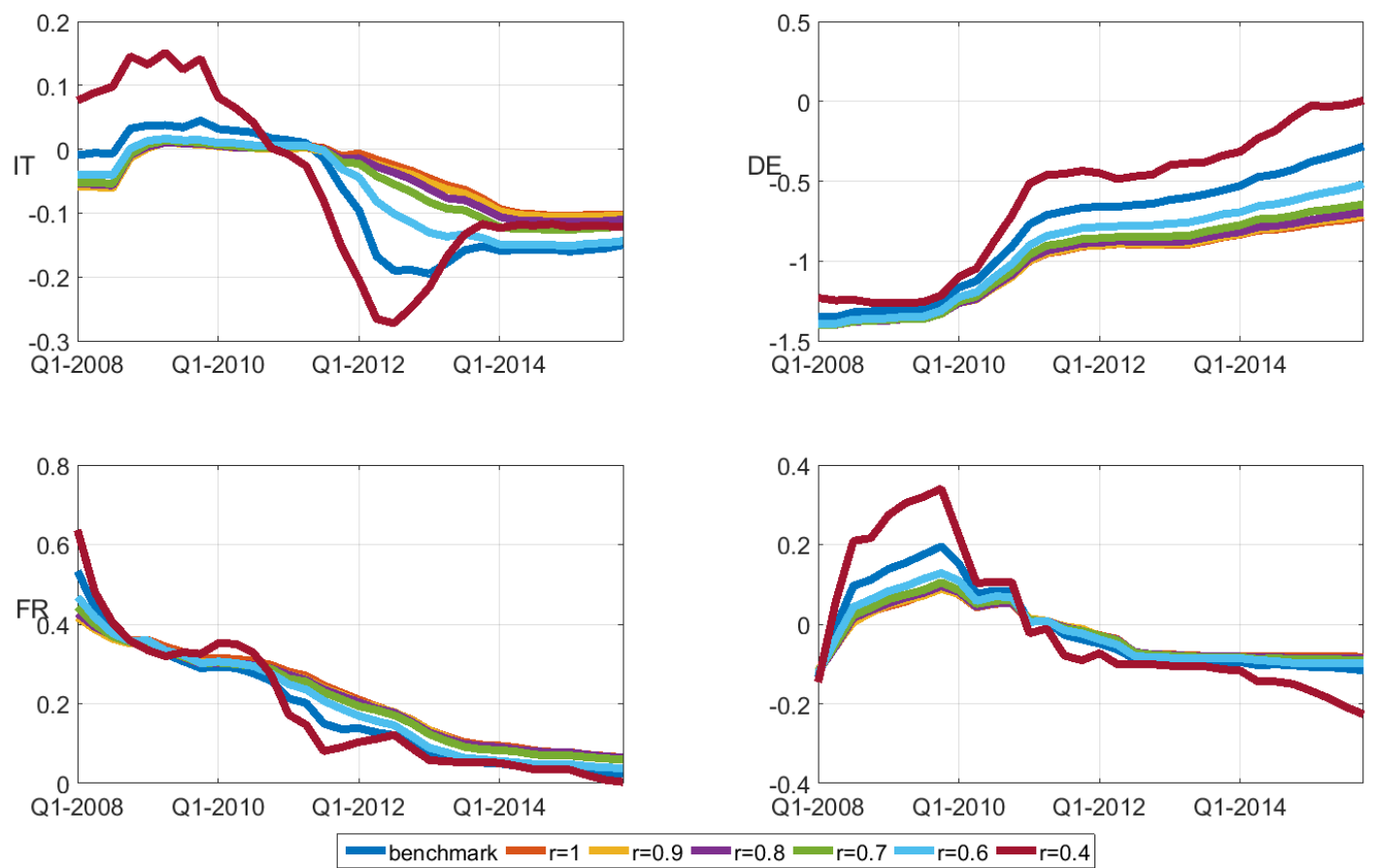
Figure 7: robustness to lag relationship between unemployment and wage dynamics

$$
\Delta^{4} w_{t}=c_{t}+\sum_{i=1}^{h} \beta_{i t} \Delta^{4} w_{t-i}+\delta_{t} E_{t} \Delta p_{t+1}+\gamma_{t} U_{t}+\varepsilon_{t}
$$

Phillips curve steepness parameter-private sector
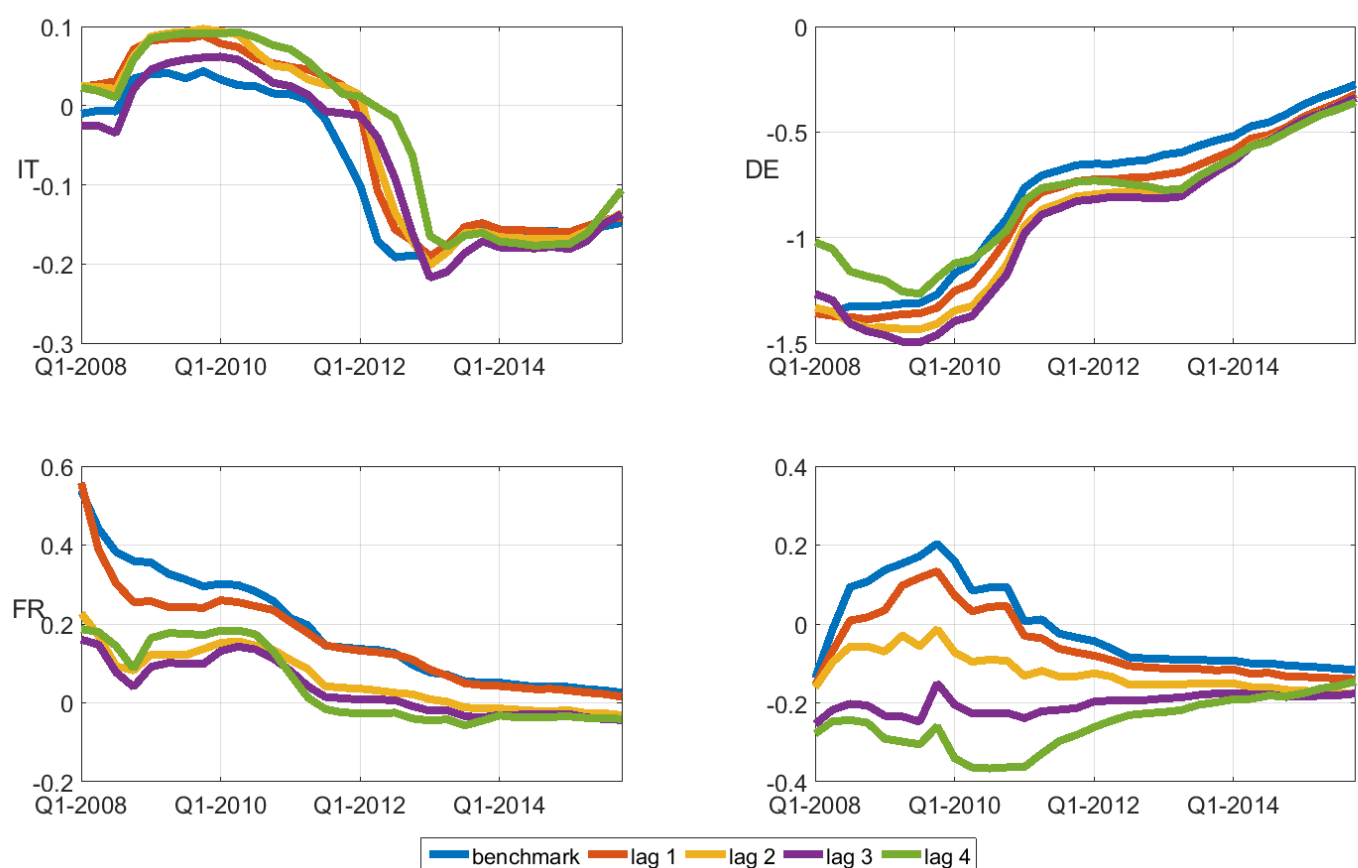
Figure 8: Phillips curve in Italy: coefficients of year dummies interacted with province level unemployment rates. Effect on wages calculated after removing composition effects and turnover.(1)

(a)- Firms

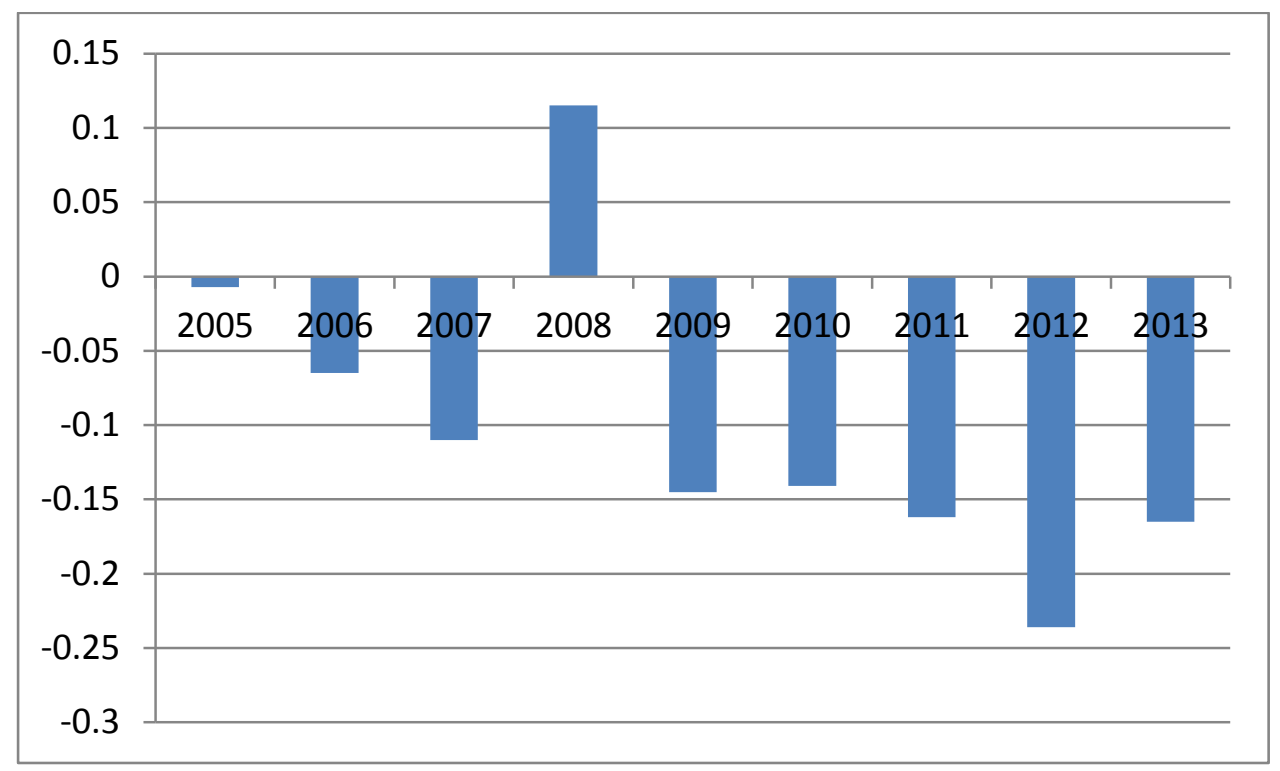

(b) - Workers

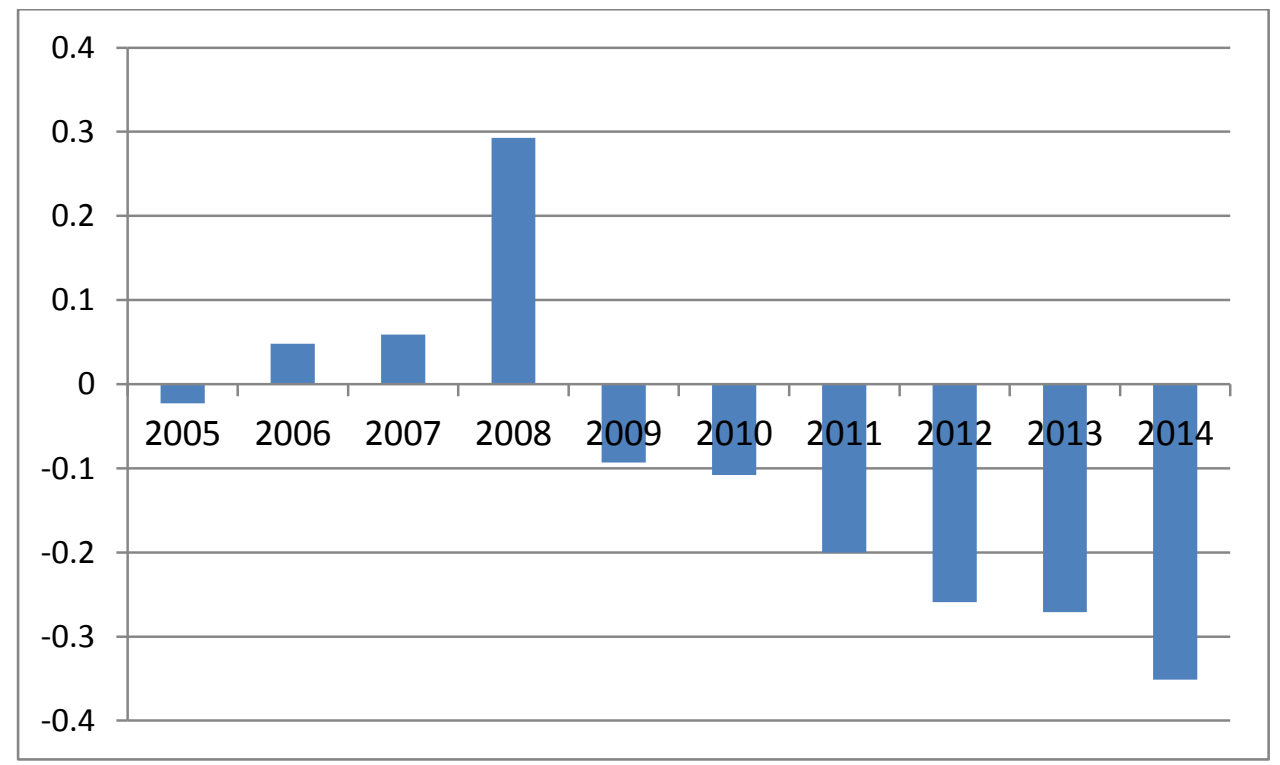

(1) INPS data. Sample of firms and workers. Robust standard errors indicate that the coefficients are negative and significantly different from zero after 2009 (at standard significance levels). 